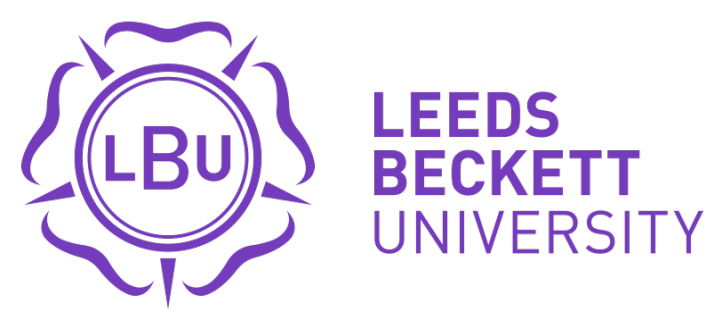

Citation:

Temple Clothier, A and Matheson, D (2019) Using Co-creation as a Pedagogic Method for the Professional Development of Students undertaking a BA (Hons) in Education Studies. Journal of Further and Higher Education, 43 (6). pp. 826-838. ISSN 0309-877X DOI: https://doi.org/10.1080/0309877X.2017.1409344

Link to Leeds Beckett Repository record:

https://eprints.leedsbeckett.ac.uk/id/eprint/4524/

Document Version:

Article (Accepted Version)

The aim of the Leeds Beckett Repository is to provide open access to our research, as required by funder policies and permitted by publishers and copyright law.

The Leeds Beckett repository holds a wide range of publications, each of which has been checked for copyright and the relevant embargo period has been applied by the Research Services team.

We operate on a standard take-down policy. If you are the author or publisher of an output and you would like it removed from the repository, please contact us and we will investigate on a case-by-case basis.

Each thesis in the repository has been cleared where necessary by the author for third party copyright. If you would like a thesis to be removed from the repository or believe there is an issue with copyright, please contact us on openaccess@leedsbeckett.ac.uk and we will investigate on a case-by-case basis. 


\title{
Using Co-creation as a Pedagogic Method for the Professional Development of Students undertaking a BA (Hons) in Education Studies
}

\author{
Anne Temple Clothier ${ }^{\mathrm{a}^{*}}$ and David Matheson ${ }^{\mathrm{b}}$ \\ ${ }^{a}$ School of Education, Leeds Beckett University, Leeds, England \\ b Faculty of Education, Health and Well-being, University of Wolverhampton, Walsall \\ Campus, Walsall, UK
}

Room 111, Carnegie Hall, Leeds Beckett University, Headingly Campus, Leeds. LS6 3GZ. A.Temple-Clothier@LeedsBeckett.ac.uk.

\begin{abstract}
Using an interpretive epistemology to explore the perceived benefits of using co-creation as a pedagogic tool with undergraduate students, this research focuses on a collaborative project between some first year undergraduate Education Studies students, a university Senior Lecturer, and an Education Coordinator from a regional social enterprise organisation. The paper is timely given the introduction of the Teaching Excellence Framework, and explores how the use of co-creation and creativity enhances the professional development and employability of Graduates. Drawing on data collected from the students, this paper presents a range of perspectives and identifies how 'meaningful' problem-solving, co-creation, and collaboration lead to transformative learning and enhanced student engagement. By doing this, we explore how complex challenges create agency for learning and develop critical thinking.
\end{abstract}

Keywords: co-creation, collaboration, critical thinking, transformative learning

\section{Introduction}

This paper explores some perceived benefits of using a multi-disciplinary, co-creation process as a pedagogical tool to enhance the personal and professional development of a group of undergraduate Education Studies students. Exploring the students' perceptions of the experience, we reveal how complex challenges may create agency for learning.

The 'co-creation' project was developed to assist a range of practitioners meet some of the challenges they faced. The subsequent research was developed to explore the students' perceptions of using the co-creation process as an alternative pedagogy, and their evaluation of its impact on learning. 
First, we present the stakeholders and context of the project, and then the theoretical grounding. We follow with a brief description of how the project developed its terms of reference, and the research methodology used to explore its efficacy for learning. Finally, the students' perceptions are presented and we conclude by identifying some of the implications for academic practitioners.

\subsection{The Stakeholders and Context.}

A Senior Lecturer (SL) in Education was searching for new ways to engage students in meaningful, and exciting professional development. An Educational Co-ordinator (EC) in a Regional Social Innovation Project (RSIP) was seeking to develop a range of activities that would engage Key Stage 1 and 2 children in thought-provoking activities to develop a healthy attitude toward cooking and nutrition. The Founder (F) of an International Social Innovation Project (ISIP) was looking for new ways to minimise the waste of the perfectly edible food surplus that he collected from local supermarkets.

The ISIP, founded in 2013 is a global network of 'Pay-as-you-feel concepts' that "divert surplus edible food destined for waste and make it accessible for human consumption" (therealjunkfoodproject, 2017). The organisation's ventures include cafes, catering, one-off events and, most recently, the establishment of Sharehouses - i.e. warehouses where surplus food, collected from supermarkets, is made available on a Pay-as-you-feel basis, a concept used to utilise the surplus food, educate the general public and campaign against global issues that food waste creates (therealjunkfoodproject, 2017).

Initially, a local primary school's headteacher developed the RSIP in partnership with ISIP as part of a bid to prevent hunger restricting educational attainment in his school. It had three main objectives, to:

- Remove hunger as a barrier to learning;

- Highlight the importance of nutrition and the associated benefits linked to learning;

- Highlight the vast amounts of wasted (yet perfectly edible) food across our local and wider community (fuelforschool, 2017).

Through the partnership, the RSIP supply food to the school which is used to provide each of the 600 pupils with a free breakfast every morning. As an analysis of the initial impact suggested "the work has truly enriched the wellbeing of children, their families and the community" (fuelforschool, 2017), plans were drawn up to expand the RSIP provision to as many schools as possible. Currently in its first year, the RSIP has developed a Service Level Agreement to supply food and education resources 
to over 60 schools. As the work of the RSIP expanded, a full-time Education Coordinator (EC) was appointed to manage the Service Level Agreements, and the educational elements of the project.

The SL, F, EC and the headteacher came together after the SL had visited the ISIP Sharehouse, the first Pay-as-you-feel supermarket in England. The headteacher invited her to visit his school and witness the RSIP project providing not only breakfasts for the pupils, but also a Pay-as-you-feel community café within the school grounds, and a Pay-as-you-feel market-stall at the school gates.

Convinced her students would be interested to hear about these initiatives, the SL invited representatives from the primary school and the RSIP as guest speakers during a Professional Development module. The students' enthusiasm indicated that they wanted a greater involvement than this one-off event, and so the possibility of a shared project was discussed. Such was the enthusiasm by the students that the SL and the EC agreed to coordinate a student project, agreeing a student commitment of notional forty hours over several months. Although still unsure as to what this project would involve, and who would participate, they invited all level 4 [i.e. first-year undergraduate] Education Studies students to an initial workshop.

We next present the theoretical grounding for the approach to teaching and learning used in the project. We then discuss how the project took shape, and defined its outcomes. This is followed by the research methodology, before presenting a review of the students' own perceptions of the benefits of their engagement.

\section{Theoretical Grounding}

The project offered an opportunity to research how the participants improved their "adaptability and survivability... by allowing (the) integration of resources that are mutually beneficial " (Vargo et al. 2008: p145) as they pursued their 'internal careers' as described by Lengel (2001) and Schein (1996). Their reflections highlight some of the "application of competencies (such as knowledge and skills)" (Vargo et al. 2008:p 145), and by doing so show what these are. This perhaps reveals some things that the participants did not know they were good at, or the transference of skills to new contexts. As such, "the process of making a new or revised interpretation of the meaning of an experience, which guides subsequent understanding, appreciation, and action" (Mezirow et al. 1990: p1) is revealed.

Candy (1989) suggests "that knowledge cannot be taught but only learned" (p107) while Garrison (1992) suggests that knowledge is the 
result of the learners integrating new ideas, perspectives, and values into existing cognitive structures and collaboratively justifying the resulting understanding. Teaching is a matter of negotiating meaning and not transmitting ready-made knowledge ( $p 142$ ).

In addition, Young and Shaw (1999) suggest that effective teaching has six key dimensions:

- the value of the subject;

- it is motivating students;

- it takes place in a comfortable atmosphere;

- there is organisation of the subject; effective communication is used; and

- there is real concern for student learning.

We explore these six elements to uncover the value of using 'co-creation' as a pedagogic tool.

According to García-Peñalvo et al. (2013):

In contrast to expert-led, institutionally-driven formal education, the 'co-creation of knowledge' is ... an educational approach which privileges peer-based support and communication, educational facilitation (rather than teaching) and learner self-efficacy (p18).

With co-creation, the power relationship between teacher/student "challenges conventional conceptions of learners as subordinates to the expert tutor/faculty in engaging with what is taught and how" (Bovill et al. 2011: p133).

Bovill et al. (2011) advocate collaborations between student and teacher, and, following Hutchings \& Huber (2010), suggest that it leads to "a more democratic intellectual community, and more authentic co-inquiry" (pxii). Bovill et al. (2011) suggest that engaging students, allowing them to take more responsibility for their learning,... [requires] engaging in meaningful (as opposed to rote) learning; staff and students breaking down the power differential between them; and students experiencing freedom to become critical thinkers and critical beings" (p133).

They suggest that this type of "active learning implies not only a shift from passivity to agency but also from merely doing to developing a meta-cognitive awareness about what is being done". Following Bain \& Zimmerman (2009: p10), they conclude:

When students make this transition from simply enacting what is required of them to learn, to analysing consciously what constitutes and enhances that learning, they change 'not just what the learner knows ... but recognize and even relish the opportunity and necessity for breaking with traditional approaches and inventing new ones' (Bovill et al. 2011: p133) 
This 'transformative learning' means that "at the end of the process the student, or their knowledge, has to some extent 'changed' into something new" (Rushton and Temple Clothier 2014: p76). There are two key dimensions to this approach, self-directed learning and critical thinking. For Garrison (1992), there is an "intimate relationship between self-directed learning and critical thinking" and that "to be a critical thinker, one needs to be self-directed; and conversely, to be a self-directed learner, one needs to be a critical thinker (p145). Although many writers note the difficulty with providing a precise definition for 'critical thinking', McPeck (2016) terms it "the judicious use of scepticism, tempered by experience" that produces "a more satisfactory solution, or insight into, the problem at hand" (p9) concluding that "the propensity and skill to engage in an activity with reflective scepticism" is key to developing critical thinking. It is this 'critical thinking' that leads to Freire's (1998) 'critical consciousness' whereby students become 'agents in the process of transformative learning' (Fielding 1999: p22) and critical beings empowered to seek liberation (Freire 1998).

Clearly there are theoretical models that would suggest a co-creation project which is perceived to have value by the students, is effectively organised, with good communication, should produce an effective opportunity for self-directed learning and lead to critical consciousness and empowerment.

Next, we detail the co-creation project itself, then the associated research and finally we review the project's contribution to the students' professional development.

\section{The Project and the Research}

\subsection{The Project}

The Project was offered to students as a 'placement' option. They would work within this group as an alternative to the more traditional work placement opportunities available to them. The placement, though not the project itself, would form part of their academic development, and the formal academic 'assessment' of their development would be conducted, via the submission of a poster presentation and reflection, to a tutor who was not part of this project. Therefore, within the project itself the SL and EC had no power to pass, or fail, any student, or indeed assess any engagement, outcomes or behaviours. Hence, there were no rules or guidelines regarding 'compliance' nor benchmarks for 'achievement' within the project. The students were allowed, and encouraged, to tell the SL and EC what to do, or to identify what they themselves would like to do, based on their interests or desired learning outcomes. From its inception, the direction or 
'outcomes' for this project developed organically. The final 'product' was jointly attributed to the students and the range of facilitators who had worked with them, and the 'quality' of the product was determined by the independent audience at its launch in March 2017.

During the first collaborative session held in December 2016, it was agreed there would be a democratic relationship between facilitators and students [following Freire (1998) and Bovill et al. (2011)], and that 'co-creation' (García-Peñalvo et al. 2013) would be the key approach utilized throughout the process.

Participants were asked to keep field diaries and record their reflections and actions as they applied their 'service' (knowledge and skills) (Vargo et al. 2008) to the project, and became 'agents in the process of transformative learning' (Fielding 1999: p22). The content of the initial workshop presented here illustrates the process by which the group's aims and objectives were agreed, and the group's working practices negotiated.

The EC began by outlining a range of current challenges regarding the development of the RSIP educational provision. Given that he was 'time poor,' this included how to evaluate and refine existing teaching and publicity material, and begin the development of an extension Education Pack to meet the demands of the second year of Service Level Agreements with participating schools.

A brief discussion revealed that students would be most interested in developing new teaching material, and the EC suggested that, if this were produced with sufficient quality, their work could be included in the second year Service Level Agreement. Having this as a specific focus provided a challenge that could be 'owned' by the group, and would lead to an output that could be credited to them. A notional deadline for the completion of the work was April 2017.

The students voiced an initial nervousness about the undertaking. However, they were somewhat reassured when it was suggested that the group would be able to meet its objectives if the students and the facilitators co-create the product. It was also agreed that whenever possible volunteer representatives from the primary school and RSIP would to join the sessions to contribute to the production of the product, and support student development. 
With the 'output' agreed, the group set about brainstorming a possible classroom activity that could be used with KS1 and 2 learners to develop an overview of some of the issues and values the RSIP seek to disseminate. The issues included:

- Food is produced globally

- A large proportion of all food produced is wasted

- Some children still go hungry

- There is enough food to feed everybody

- A healthy diet is essential to well-being

- The Eatwell Guide

Ideas came in profusely, and student engagement was high. Throughout the remaining commitment to the project, students and facilitators worked together to create, and coordinate a range of learning activities. On one occasion, a volunteer from the RSIP joined the working group and talked about how he used his Information Technology skills to help promote the work of the RSIP, and why he chose to give his time and experience to support the work of this particular innovation. He said he found his involvement with the RSIP personally rewarding and satisfying, and it was apparent that this resonated with the students' own experiences. In addition, on five occasions a teacher from the primary school attended the sessions. He talked about witnessing the impact of the RSIP within the school, predominantly as regards how the breakfast club, was having a beneficial impact on the behaviour and academic development of the children. He described the impact within the local community, and reported that RSIP had greatly assisted in integrating the school into the local community, and that a Pay-as-you-feel market stall was replenished at the school gates every morning, with an honesty box to collect the payments. The students enjoyed hearing about his personal and professional involvement with the initiatives, and it helped them visualise the application of their endeavours. We would suggest that these experiences enriched the students' perceptions of working outside a 'purely academic' context.

Throughout the project, activities were dynamic and participants needed to exhibit flexibility and reliability. On the occasions when respresentatives from RSIP and LPS joined the group, their involvement was warmly received by the students who enjoyed questioning them about their professional practice and expereinces. By the end of the project, the group had achieved far more than they had anticipated, and had produced a comprehensive Education Pack that covered all the learning outcomes identified in the National Curriculum (2016) for KS1 and 2 Cooking and Nutrition. The Pack contained a complete set of lesson plans, and all the supporting documentation needed to facilitate effective learning. The Pack was subsequently 'launched' at the university by the students, RSIP and ISIP to an audience of regional primary school representatives,. The students' responses to 
the process, and the areas of professional development derived from it are outlined in the final section of this paper. First, however, we present the research stance taken and methodology used to collect the data.

\subsection{The research}

Given that this project was to some degree experimental, the SL consulted with a neutral Academic Researcher (AR) and together they scoped out a research strategy to explore the students' perceptions of using this co-creation process alternative pedagogy, and their evaluation of its impact on personal and professional growth. It was agreed that the SL would collect the data as the project unfurled, and that after the close of the project the SL and AR would write up the findings. In this sense, the research and the subsequent paper is a distinct element of the project's process, and its co-creation is limited to these two academics. All the research was conducted in accordance within the Research and Ethics regulatory framework of the University, and it was highlighted to the students that participation in the research was not part of the project activity, and participation was voluntary.

The seventeen first-year undergraduate Education Studies students involved in the project provided a convenient sample, allowing a qualitative approach to data collection using semi-structured interviews, informal focus groups, and field notes.

We maintain that the 'social phenomena' which form the 'social world' are "only real in the sense that they construct ideas which are continually being reviewed and reworked by those involved with them"(Matthews and Ross 2014 p.24), and hence our ontological position is that of constructivism whereby it is possible to suggest that there is "no social reality apart from the meaning of the social phenomenon for the participants"(Matthews and Ross 2014 p.24). However, it is the participants' explanations and understanding of the significance of their development that provides the focus of this research. It is also important to note that, as researchers and therefore part of this social construct, we apply our own meanings and understanding to the research.

An interpretivist epistemological position was adopted, which sits easily within the constructivist approach as "the nature of a social phenomenon is in the understanding and meaning ascribed to the social phenomenon by the social actor"(Matthews and Ross 2014 p.28). 
Primary data were collected by the SL using qualitative methods, including field notes, a series of 30minute semi-structured focus groups conducted at various points of the development process, and individual semi-structured interviews. The field notes were the researchers' aides-memoire, and included observations, and reminders of issues needing possible clarification.

The focus groups and interviews took place at the end of the project's working sessions. This was to make the data collection as unobtrusive as possible; also, any student not wishing to take part could leave comfortably before data collection began (though this opportunity was never taken). Obtaining the students' reflections after the group activites served as a wind-down and provoked evaluatory reflections before each session closed. Also this emphasised that the research was secondary to the project itself, and this is reflected in the timing of the data-gathering. The students were at ease with each other after working together, making it more likely to lead to open and honest reflections. Both the focus groups and interviews were relatively informal and participants were encouraged to reflect on the processes, and learning, experienced throughout the project. The data was recorded either in note form or audio-recorded and transcribed later.

All that was asked of participants was that they provide honest answers and that they determine the level of comfortable disclosure. They were questioned about the processes they were undertaking, and no personal or sensitive data was sollicited.

The person collecting the data had worked with the students over a number of weeks, which, therefore, may have impacted on the reliability, validity and truthfulness of the responses. It is also possible that, during the focus groups, some students felt inhibited talking in front of their peers, and for that reason the individual interviews were used to overcome the potential short-comings of the focus groups. Throughout the focus groups, and interviews, students had the right to not answer any question they were uncomfortable with. No one chose to avoid answering any question, or take the opportunity to withdraw from the research. We conclude that it is unlikely that anyone felt coerced or obligated; there were no actions or comments that would indicate this to be the case.

However, it is also possible that the students may have exhibited 'social desirability' in their responses; either by aiming to present themselves in the best light possible, or provide the answers they thought the researcher wanted to hear. If this were the case, then again the lack of honesty would lower the validity of our findings. However every effort was made to ensure that this did not 
happen. In this instance, we believe that the established relationship of trust, and existing rapport between researcher and participants, had a beneficial effect on the data collection.

A review of the data collected throughout the research process, and the evaluation meeting held at its close revealed that there were a number of key competencies that students felt had been developed during the project. They perceived that this successful and effective learning had, in turn, had a significant impact on their scholarly ability, professional identity, and enhanced their employability.

\section{Student Perceptions}

In order to uncover if the co-creation process had provided an effective pedagogy for personal and professional development, the student comments and perceptions were coded against Young and Shaw's (1999) six dimensions of effective teaching:

- the value of the subject;

- that it is motivating students;

- that it takes place in a comfortable atmosphere;

- there is organisation of the subject; effective communication is used; and

- there is real concern for student learning.

\subsection{The value of the subject.}

It was apparent that the issues addressed by both the ISIP and RSIP had resonated with the values of the student group, and this had encouraged and maintained a strong sense of engagement throughout. Indicative comments included "It is an organisation that really sparked my interest", and "We believed in the values of the project and I am very proud of what we have achieved together". The students' reflections suggest that Garrison's (1992) assertion that there is a relationship between self-directed learning and the development of critical thinking has resonance as this student explains her reasons to participate:

When I'm working on something I value, it's not difficult to make the time to do it, and it's more rewarding. I chose this project because I wanted to make the most of every opportunity during my time at the university, and doing this really helped me understand both the course material, and the profession I want to move into.

Reflections made at the close of the project also suggest that it was the 'value of the subject' (Young and Shaw 1999) in terms of focus, and career development that had created meaningful learning (Bovill et al. 2011: p133): 
Working on a project that would have a real-life impact is much more motivating, you can see the relevance of your work, and it is not a 'scenario' or 'role play'. I was highly motivated throughout this activity, I could see the relevance to my own career development, and every time I learned something new it felt really beneficial both personally and professionally.

This suggests that the active learning within the project had indeed led the student to "recognize and even relish" (Bovill et al. 2011: p13) the opportunities within the co-creation process. In addition, the students recognized the contribution the learning had made in terms of their personal and professional development, and as such it has value within their 'internal careers' (Lengel 2001; Schein 1996).

\subsection{That it is motivating students.}

The infectious nature of the students' commitment was referred to by a number of them. Indicative comments included "I've been really proactive throughout this work... It's been really good fun" and "Some of the tasks were quite tough, but you must make sure all the work is done, I don't want to let anyone down" and "It is exciting to work with self-motivated individuals, their energy keeps the project moving along quickly and effectively" and "The tutors are all really passionate about what they do, they got us all doing things we did not think we could do". This would suggest that, at least to some extent, that these students "engaging in meaningful ... learning" (Bovill et al. 2011: p133), having perhaps gone some way to experiencing the "democratic intellectual community, and more authentic co-inquiry" advocated by Hutchings \& Huber (2010: pxii) and Freire (1998), and perhaps relished "the opportunity and necessity for breaking with traditional approaches" to learning (Bain and Zimmerman 2009: p10).

\subsection{That it takes place in a comfortable atmosphere.}

Whilst all the workshops took place in a classroom, and with the SL who was familiar to the students, it was the changing relationships within the student group that generated the most responses regarding the comfortable atmosphere necessary for effective teaching and learning (Young and Shaw 1999).

The changing dynamics of working in various small groups, impacted greatly on the overall atmosphere of the group. Whilst there was a degree of uncertainty, and lack of familiarity at the beginning of the project, many students commented on the changing relationships and organic development of a group identity. Tuckman's (1965) Theory of Group Development appears in most, 
but not all, of the reflections. By applying the academic underpinning provided in other aspects of their study, the students evidenced the ability for "integrating new ideas, perspectives" (Garrison 1992 ) into their reflections as shown by the following example:

Due to the project involving a lot of group work I feel I experienced the Stages of Group Development, developed by Bruce Tuckman (1965). The first stage 'Forming' is the initial step to becoming a working group. The first day ended up being very productive, everybody was contributing and we managed to make a good start. Tuckman says this is due to everybody wanting to fit in and make a good first impression. The second stage is 'Storming'. This stage consists of confrontation. The next time our group met up, the dynamics were different. More people in the group were voicing their opinions and disagreeing with others which led to some controversy. However, the issues were resolved quickly and we were still able to think of good ideas. The third stage which is 'Norming' came into effect when I noticed there was a leader in the group who voiced their opinions more than others. People were given their roles and did not waver from them much. In the future, I would like to be able to voice my thoughts clearly and not be intimidated by what others might say. However, I definitely feel as though working in groups has helped me to be more imaginative with my ideas because I was hearing different people's perspectives. I also believe it has made me more employable as I am more confident about being able to make a positive contribution to in a group of people I have not worked with before.

The reflections suggest that not only did this process allow for critical thinking about their professional development, but that the students became more strategic in the "application of competencies" (Vargo et al. 2008) to guide "subsequent understanding, appreciation and action" (Mezirow et al. 1990: p1):

We began to be aware of each other's personalities and work preferences. Once we knew what each person was good at we could start to use those skills. For example, those who were good on Information Technology (IT) were used to create the PowerPoints and visual aids. Those that were good at research were given the jobs to find out additional information.

Another reflection, again referencing Tuckman (1965), gives an indication that the "comfortable atmosphere" Young and Shaw (1999) advocate, and the "democratic intellectual community" (Hutchings and Huber 2010) were indeed achieved: "This theory is very useful as it shows how a group can work together in a trustworthy environment, regardless of personal differences"

\subsection{There is organisation of the subject.}

The uniqueness of the project, and its wide-ranging activities, required a fresh approach to learning (Bovill et al. 2011) and this impacted on the organisation and planning involved. One of the dominant themes emerging from the data regarding the organisation of the project was the need to 
develop, and maintain, flexibility and adaptability. One said "I don't think that there is any other element of university work that has required us to be so adaptable". Another said:

All the workshops have been on weekends and our days off university, and l've successfully organised things to make this work. I've had to be adaptable in the way I meet the needs of the various stakeholders. On one level, I had to anticipate what KS1 and KS2 learners may enjoy as a learning experience, I also had to work around the [RSIP] values, and at the same time meet the needs of the National Curriculum so that the teachers who use our product will find it fits easily with their professional practice. I've had to adapt my approach when working with people from different ages, sectors and professional disciplines.

This indicates that the "intimate relationship between self-directed learning and critical thinking" (Garrison 1992) is evident, and the 'service' of students is adapted to meet the needs of a variety of stakeholders in ways that ensure "the integration of resources are mutually beneficial" (Vargo et al. 2008: p145). An alternative need for adaptability was referenced by another, who focuses on the variety of ways she applied her competencies to the project:

Because we were never quite sure who we would be working with, or what we would be working on, we had to show up and then get on with whatever needed doing. This meant that sometimes I was working on my own, other times I was working as part of a group of five. Sometimes we worked quietly on the computer and at other times we were discussing what to do next.

However, the agency for self-directed learning was not always comfortable for the participants:

We had to work in many small groups as we designed various learning activities, we had little time to think about it, or organise our own groups. I was forced out of my comfort zone and had to engage with many different people. Although I didn't necessarily like this, I did find that my confidence grew. We all contributed ideas, and although not all of them were acted on, they were not viewed with any negative judgements either. I found as time passed I was less afraid of offering my own opinion.

Despite the discomfort, the relationship between self-directed learning and critical thinking can be seen in the following description of the application of a creative response to problem-based learning:

One of my specific tasks was to create a lesson that taught children how to cook a basic meal. This included the importance of safe knife skills, different ways to prepare ingredients and how to boil, fry and bake. We'd to be creative to solve the problem of how to teach this and we had to consider the legal and ethical dimensions of our solutions, such as how many teachers there would be in the room compared to the number of children. We dedicated one activity to teaching the children safe motor skills such as chopping, peeling, and grating. I suggested that we use the bread from [RSIP] as a safe item to chop and grate, I also suggested dry pasta would be good for measuring activities. These items would lead to less mess, and still give the children good hands-on experience. 
It was a cost effective and creative way to teach the children about avoiding waste and being more creative with food.

The student reflections on learning evidence that they were making "new or revised interpretation of the meaning of an experience, which guides subsequent understanding, appreciation and action" (Mezirow et al. 1990: p1) in relation to their "internal careers" (Lengel 2001; Schein 1996).

For some of the aspiring teachers involved in this project, it was the first time they had felt 'critically conscious' (Freire 1998) of what goes into creating a formal lesson or learning activity. An indicative comment was "I had not given much thought about what shaped classroom activities. I assumed teachers just took the National Curriculum and designed their own classroom activities to ensure the subject was covered in the timescale." One details how she engaged with the policy framework, and reflects on the learning process itself.

The National Curriculum (NC) for Key Stages 1 and 2 Cooking and Nutrition was highlighted in the first meeting. This provided an overall framework against which to map and plan our activities. However, I think the [RSIP] agenda is more ambitious than the NC, they encourage young students to be analytical, acknowledging the real price of food, to develop an understanding about the importance of not wasting it. This notion of getting people to think critically is presented in the concept of 'Critical Consciousness' developed by the Brazilian pedagogue and educational theorist Paulo Freire (1970). The aim is to develop an awareness of social, political, and economic oppression and to take action.

A shared theme across the respondents was a deeper reflection on the formal processes governing the learning of KS1 and 2 pupils, and an increased awareness of how policy informs practice. It was the reflections concerning comparisons between the National Curriculum's intended outcomes and the RSIP values that generated the most comments characterised by the "reflective scepticism" that McPeck (2016) suggests indicates critical thinking.

However, it was not only the 'actions' of the group that were identified as being beneficial. The importance of reflection was identified by some of the students. One referenced the importance of Schön's (1983) 'reflection-in-action' as a dynamic part of the learning process.

The reflection-in-action process identified by Schön allows educators to 'construct a new theory of the unique case' (1983, p.68), meaning that the person reflecting upon a particular situation, adapts and decides what works best for that 'unique case'.

She concludes "We needed to be creative if we were to succeed. It wasn't only the planning that was important." This process of "revised interpretation of the meaning of an experience" (Mezirow et al. 1990: p1) leads to a more rueful reflection from another: 
We were asked write a short reflection after each session, on what we had learned. As I am reflecting now I regret not always completing them. Dewey (1910) said that the definition of reflective learning is "the active, persistent and careful consideration of any belief or supposed form of knowledge in the light of the grounds that support it". I believe that I could have potentially taken more from the activities if I had gone over all of the information and reflected on it. However, at the time I was completing other work. This makes me think that although I did everything well, there is still room for improvement, and adapting my approach in the future may benefit me professionally.

Whilst this statement may not exhibit the "judicious use of scepticism" in McPeck's (2016) definition of critical thinking, it is hoped that any subsequent changes in behaviour may enhance the future self-directed learning of this particular respondent.

\subsection{Effective communication is used.}

Given the unique dynamics of this project, and the lack of formal coordinated teaching, it was interesting to discover students percpetions of this co-creation 'problem-solving' approach to learning, and its impact on communication within the group. There were no comments that indicated that communication within the working group had hindered learning.

Interestingly it was the 'negotiation' with others and the 'revised' relationships with peers and facilitators that proved to be the elements of the project that the students found most challenging and rewarding. Many of the students suggested they felt their communication skills had improved as a result of their participation. An indicative comment was:

I've had to communicate with people from a wide range of backgrounds, and my confidence in my own communication skills has grown. I have had to negotiate to get my ideas incorporated in the workshop activities, and develop my written communication skills when designing lesson plans and classroom activities. I've also developed my ability to present my ideas using Information technology, particularly when producing learning items and visual displays.

Students also evidenced a growing awareness of the potential barriers to learning caused by ineffective communication. Here one focuses on the communication challenges when faced with developing learning opportunities for Key Stage 1 and 2 children with English as a Second Language (ESL):

It was important to produce visual aids, to break down the barriers to communication with young children who might have English as a second language. 47 languages are spoken in [the primary school], and as a consequence we translated some of the teaching materials into a range of other languages. 
Many reflected on the need to moderate the complexity of language used, and adapt teaching material accordingly. Also, they were very aware of the role Information Technology played in terms of assisting communication. An indicative comment was:

We used IT to provide a range of resources that could communicate ideas to KS1 and KS2 pupils. We were aware that they require a very difference type of communication to the language used within the university. We used pictures wherever possible to communicate more effectively with a wider audience.

One of the most sophisticated reflections, from an aspiring teacher, displayed a more in-depth understanding of the teaching and learning processes

The idea of professionalism was highly emphasised whilst we were creating the learning activities. In a multi-cultural institution, such as [the school] the levels of ability among students can vary greatly, therefore it is vital to differentiate within the class.

Interestingly the reference to 'differentiation' would also suggest that at least some of the students were engaging with the language of teaching (meta-language), and as such beginning to assimilate the communication terms of this particular community of practice.

The impact of the communication within the project had a wider implication for students, an indicative comment was "I've also noticed that I now contribute more to classroom discussion within the other taught sessions of my course. I see this as a transferable skill developed within placement, now applied to my studies in general".

This section has revealed how the students were able to critically reflect on their experiences, and apply their knowledge and skills (Mezirow et al. 1990; Vargo et al. 2008) concerning communication to both the project and their wider professional development (Lengel 2001; Schein 1996). As such, it would suggest that through addressing issues relating to communication, the students had indeed become "agents in the process of transformative learning" (Fielding, 1999) p.22) and as a consequence “changed into something new" (Rushton and Temple Clothier 2014: p76).

\subsection{There is real concern for student learning.}

Throughout the project the students displayed enthusiasm, high motivation and excellent engagement and this would support Bovill et al's assertions that when "[t]aking more responsibility for their learning [students] recognize and even relish the opportunity" (2011: p133). Whilst exhibiting a real concern that the material produced would lead to positive outcomes, the students deepened their own conceptual understanding of learning and achieved professional development. 
Throughout the project the focus was on producing the 'output' of the Educational Pack, and the focus on undergraduate learning only appeared in the student reflections. Whilst the output itself evidences the "application of competencies" (Vargo et al. 2008: p145), it was the reflections that evidenced an increase in self-direction and critical thinking (Garrison 1992), reflective scepticism (Mc Peck 2016), and the application of theoretical underpinning.

One student noted:

Freire's (1996) multi-layered theory... sees the traditional teacher-student relationship as oppressive. In the 'banking education system' the student is seen as a passive individual. He developed a system called 'problem-posing education' in which learners are not only encouraged to think, but also to interact within a greater dialogue. This intensifies the relationship of teachers and learners in terms of critical consciousness leading to the establishment of dialogues and resolution of problems. This project has really helped me understand what this theory means.

The "educational facilitation" and "learner self-efficacy" advocated by García-Peñalvo et al. (2013) had resulted in students (in their own words) being taken "out of their comfort zone". This pedagogy led them to conclude "It was interesting to have 'problem-solving' as the main focus for our activities ... I think it's an interesting and effective way to learn, and it made the time pass quickly" and "When problem-solving is used to create effective learning you need creativity and resilience to do it well".

All of the students indicated that they felt more 'employable' as a result of participating in the project, and as such viewed it as meaningful and 'transformative' (Rushton and Temple Clothier 2014). This suggests that the process, and the outcomes, were relevant to their internal careers (Lengel 2001; Schein 1996) and valued by the respondents.

\section{Conclusion}

Although the Project had started out as an experimental problem-solving exercise for a range of practitioners, and subsequently created a development opportunity for students, all concerned with the project viewed it as a highly enjoyable and productive experience.

The co-created outputs exceeded initial expectations, and a collation of student reflections evidenced a deeper engagement with the issues associated with teaching and learning. 
The revised relationship with facilitators and peers had resulted in increased self-confidence, and self-authorship of the students. Skills and knowledge accrued within the project were being transferred to the broader professional and scholarly development across the undergraduate course.

The students recorded the experience in their ePortfolios to continue to be part of their recorded professional development.

Whilst we recognise that this type of project has great value within the formal structure of an undergraduate course, we also acknowledge the serendipity associated with its creation. It would be problematic to mandate the inclusion of co-creation in an undergraduate course, since a focus for meaningful engagement is not always easy to define, and the 'relinquishing of power' associated with the facilitation approach may not necessarily be a comfortable position for the academic practitioner. However, we recommend considering the value of co-creation as a pedagogic method, and viewing favourably opportunities for collaboration. This requires the support of the academic institution and an experimental engagement, with evaluation, to explore the success in terms of student perceptions of the impact on learning.

Future research could include interviewing the respondents a year after their engagement with this project to see what hindsight offers regarding the effect on their personal and professional development. It would also be interesting to interview the practitioners involved in this project and ascertain what they perceive to be the advantages and disadvantages of their own engagement. For now, we conclude: we were lucky, it was meaningful, it was developmental, and perhaps most of all it was fun. 


\section{References}

Bain, K. and J. Zimmerman. 2009. Understanding great teaching. Peer Review 11, no 2: 9-12.

Bovill, C., A. Cook-Sather and P. Felten. 2011. Students as co-creators of teaching approaches, course design, and curricula: Implications for academic developers. International Journal for Academic Development 16, no 2: 133-45.

Candy, P.C. 1989. Alternative paradigms in educational research. The Australian Educational Researcher 16, no 3: 1-11.

Dewey, J. 1910. The influence of darwin on philosophy. New York: Henry Holt \& Co.

Fielding, M. 1999. Target setting, policy pathology and student perspectives: Learning to labour in new times. Cambridge Journal of Education 29, no 2: 277-87.

Freire, P. 1970. Pedagogy of the oppressed. New York: Herder and Herder.

Freire, P. 1996. Pedagogy of the oppressed (revised). London and New York: Continuum.

Freire, P. 1998. Pedagogy of freedom: Ethics, democracy, and civic courage. New York: Rowman \& Littlefield.

García-Peñalvo, F., M. Conde, M. Johnson and M. Alier. 2013. Knowledge co-creation process based on informal learning competences tagging and recognition. International Journal of Human Capital and Information Technology Professionals (IJHCITP) 4, no 4: 18-30.

Garrison, D. 1992. Critical thinking and self-directed learning in adult education: An analysis of responsibility and control issues. Adult Education Quarterly 42, no 3: 136-48.

Hutchings, P. and M.T. Huber. 2010. Citizenship across the curriculum. Indianapolis: Indiana University Press.

Lengel, L. 2001. The information economy and the internet. In Journalism and mass communication, ed. Luthra, R. Paris: UNESCO-EOLIS 22-44.

Matthews, B. and L. Ross. 2014. Research methods. London: Pearson Longman Higher Education.

Mc Peck, J. 2016. Critical thinking and education. Abington: Routledge.

Mezirow, J., S. Brookfield and P.C. Candy. 1990. Fostering critical reflection in adulthood: A guide to transformative and emancipatory learning. San Francisco: Jossey Bass.

Rushton, I. and A. Temple Clothier. 2014. Selecting appropriate content. In Learning, teaching and development: Strategies for action, eds Ashmore, L and Robinson, D. London: Sage p 70-98.

Schein, E. 1996. Career anchors revisited, implications for career development in the 21st century. Academy of Management Executive 10, no 4: 80-88.

Tuckman, B.W. 1965. Developmental sequence in small groups. Psychological bulletin 63, no 6: 38499.

Vargo, S.L., P.P. Maglio and M.A. Akaka. 2008. On value and value co-creation: A service systems and service logic perspective. European Management Journal 26, no 3: 145-52.

Young, S. and D.G. Shaw. 1999. Profiles of effective college and university teachers. The Journal of Higher Education 70, no 6: 670-86. 